\title{
TRANSMIT POWER CONTROL ANALYSIS IN V2X COMMUNICATION SYSTEM
}

Transmit power control is applied for reduction of transmission power to the level needed for reliable communication. The article describes problematic of transmit power control in ad-hoc V2X communication system applied in intelligent transport system environment.

Key words: transmit power control, inter-vehicle, roadside-to-vehicle, V2X communication system, intelligent transport system

\section{Introduction}

Present day communication technologies as well as microelectronics allow production of reliable and low energy consumption devices suitable for intelligent transport system (ITS) applications, [1]. Communication platform became integral part of ITS infrastructure.

In 1999, U.S. Federal Communication Commission (FCC) allocated $75 \mathrm{MHz}$ spectrum at $5.9 \mathrm{GHz}$ for Dedicated Short Range Communications (DSRC) devices to be used for car-to-car as well as car-to-road infrastructure communications. The primary goal of above mentioned decision was to improve traffic flow and safety aspects of public road transport.

On $5^{\text {th }}$ August 2008, the EU Committee decided to allocate a frequency band from 5875 to $5905 \mathrm{MHz}$ for ITS applications, which is going to be used on non-exclusive basis. Intelligent trans-

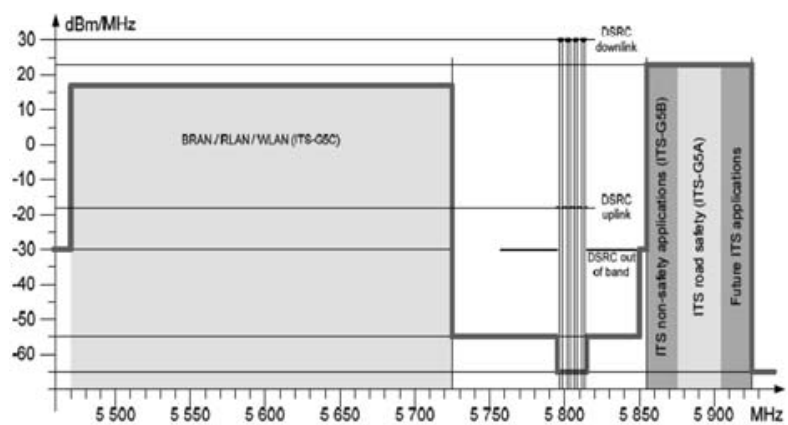

Fig. 1 Maximum limit of mean spectral power density (EIRP) port V2X communication frequency band as well as maximum limit of mean spectral power density (EIRP) is illustrated in Fig. 1, [2]. Inter-vehicle (IVC) and roadside-to-vehicle (R2V) communication is permitted in all of frequency bands.

Channel allocation is defined as specified in table 1, [3]. One physical channel is allocated as a G5CC and four fixed channels are identified as G5SCs.

G5CC and $\mathrm{G} 5 \mathrm{SC} 1$ to $\mathrm{G} 5 \mathrm{SC} 4$ are dedicated for the following usage:

- The G5CC shall be used for road safety and traffic efficiency applications and may be used for ITS service announcements of services operated on G5SC1 to G5SC4.

- G5SC1 and G5SC2 shall be used for ITS road safety and traffic efficiency applications.

- G5SC3 and G5SC4 shall be used for other ITS user applications.

Fig. 2 presents power density limits of ITS transmitting units at a frequency band of $5.9 \mathrm{GHz}$. Transmit power limit as well as power density limit for a defined channel is presented in table 1. Maximal transmit power limit equal to $33 \mathrm{dBm}$ was defined on the basis of the study of electromagnetic compatibility between ITS and other radio systems for fixed, mobile and satellite services, [4].

The total RF output power and the power spectral density when configured to operate at the highest stated power level of the transmit power control (TPC) range shall not exceed the levels of $33 \mathrm{dBm}$ and $23 \mathrm{dBm} / \mathrm{MHz}$, respectively. The total RF output power and the power spectral density when configured to operate at the lowest stated power level of the TPC range shall not exceed the levels of $3 \mathrm{dBm}$ and $-7 \mathrm{dBm} / \mathrm{MHz}$, respectively, [4], [7].

\footnotetext{
* Juraj Micek, Jan Kapitulik

Faculty of Management and Informatics, University of Zilina, Slovakia, E-mail: juraj.micek@fri.uniza.sk
} 


\begin{tabular}{|c|c|c|c|c|c|c|}
\hline $\begin{array}{c}\text { Channel } \\
\text { type }\end{array}$ & $\begin{array}{c}\text { Centre } \\
\text { frequency }\end{array}$ & $\begin{array}{c}\text { Channel } \\
\text { number }\end{array}$ & $\begin{array}{c}\text { Channel } \\
\text { spacing }\end{array}$ & $\begin{array}{c}\text { Default data } \\
\text { rate }\end{array}$ & $\begin{array}{c}\text { TX power } \\
\text { limit }\end{array}$ & $\begin{array}{c}\text { TX power } \\
\text { density limit }\end{array}$ \\
\hline $\mathrm{G} 5 \mathrm{CC}$ & $5900 \mathrm{MHz}$ & 180 & $10 \mathrm{MHz}$ & $6 \mathrm{Mbit} / \mathrm{s}$ & $33 \mathrm{dBm} \mathrm{EIRP}$ & $23 \mathrm{dBm} / \mathrm{MHz}$ \\
\hline $\mathrm{G} 5 \mathrm{SC} 2$ & $5890 \mathrm{MHz}$ & 178 & $10 \mathrm{MHz}$ & $12 \mathrm{Mbit} / \mathrm{s}$ & $23 \mathrm{dBm} \mathrm{EIRP}$ & $13 \mathrm{dBm} / \mathrm{MHz}$ \\
\hline $\mathrm{G} 5 \mathrm{SC} 1$ & $5880 \mathrm{MHz}$ & 176 & $10 \mathrm{MHz}$ & $6 \mathrm{Mbit} / \mathrm{s}$ & $33 \mathrm{dBm} \mathrm{EIRP}$ & $23 \mathrm{dBm} / \mathrm{MHz}$ \\
\hline $\mathrm{G} 5 \mathrm{SC} 3$ & $5870 \mathrm{MHz}$ & 174 & $10 \mathrm{MHz}$ & $6 \mathrm{Mbit} / \mathrm{s}$ & $23 \mathrm{dBm} \mathrm{EIRP}$ & $13 \mathrm{dBm} / \mathrm{MHz}$ \\
\hline $\mathrm{G} 5 \mathrm{SC} 4$ & $5860 \mathrm{MHz}$ & 172 & $10 \mathrm{MHz}$ & $6 \mathrm{Mbit} / \mathrm{s}$ & $0 \mathrm{dBm} \mathrm{EIRP}$ & $-10 \mathrm{dBm} / \mathrm{MHz}$ \\
\hline
\end{tabular}

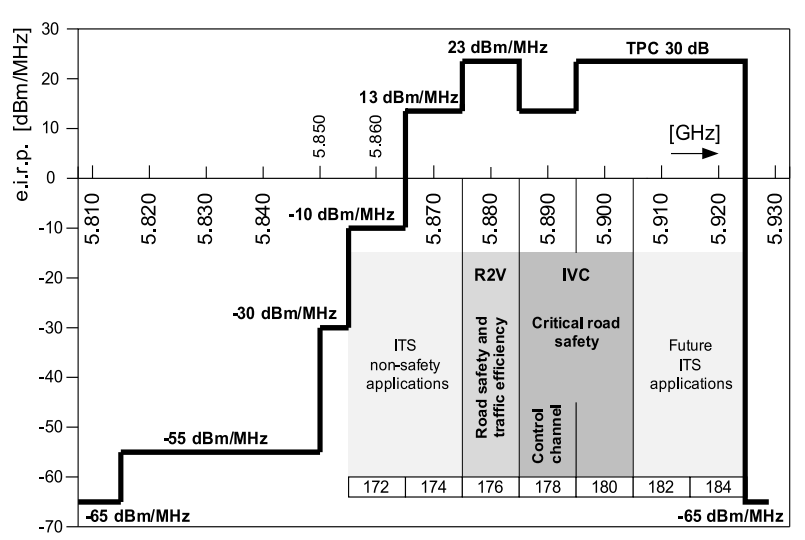

Fig. 2 Power density limits of ITS transmitting units at frequency band $5.9 \mathrm{GHz}$

V2X communication system allows dynamic control of transmit power of a device in a range of $30 \mathrm{~dB}$. Settings of the transmit power shall be in steps of $0.5 \mathrm{~dB}$ controlled by the congestion control manager. Half-duplex and broadcast data transmission mode is supported. [3].

Data rates for $10 \mathrm{MHz}$ channel spacing are defined in table 2,

\section{RF Output power analysis}

As it was mentioned above, V2X communication system supports dynamic control of transmit power of a device to support scalable and reliable communication between communication units of V2X network. Transmit power control block plays one of main roles in sense of guarantee high quality communication between vehicles as well as roadside units and vehicles.

The analysis of RF output power delivered to the transmit antenna could be principally based on adaptation of Friis trans- mission equation utilizing a proper radio propagation model that represents path loss between two on-board units (OBU) or roadside unit (RSU) and on-board unit (OBU) of a vehicle. Path loss models accepted by standardization bodies will be used in the analysis.

Friis transmission equation

Mathematical model of Friis transmission equation is as follows, [5]:

$$
P_{R} / P_{T}=G_{T} \cdot G_{R} \cdot(\lambda / 4 \pi \cdot d)
$$

where:

$G_{T}$ and $G_{R}$ are the antenna gain of the transmitting and receiving antennas, respectively, $\lambda$ is the wavelength, $d$ is the distance. The inverse of the factor in parentheses is the so-called free-space path loss. This simple form applies only under the following ideal conditions:

- The antennas are in unobstructed free space, with no multi-path.

- $P_{R}$ is understood to be the available power at the receive antenna terminals.

- $P_{T}$ is understood to be the power delivered to the transmit antenna.

- The bandwidth is narrow enough that a single value for the wavelength can be assumed.

Equation (1) is possible to rewrite to logarithmic form as follows:

$$
P_{T}=P_{R}-G_{T}-G_{R}+L,
$$

where:

$P_{T}$ is the transmit power in $\mathrm{dBm}$,

$P_{R}$ is the received power in $\mathrm{dBm}$,

$G_{T}$ is the transmit antenna gain in $\mathrm{dBi}$,

$G_{R}$ is the receive antenna gain in $\mathrm{dBi}$,

Data rates and channel spacing

Table 2

\begin{tabular}{|l|c|c|c|c|c|c|c|c|}
\hline Modulation coding scheme (MCS) & 0 & 1 & 2 & 3 & 4 & 5 & 6 & 7 \\
\hline Data rate in Mbit/s 10 MHz channel & 3 & 4.5 & 6 & 9 & 12 & 18 & 24 & 27 \\
\hline Modulation scheme & BPSK & BPSK & QPSK & QPSK & 16 -QAM & 16-QAM & 64 -QAM & 64 -QAM \\
\hline Coding rate R & $1 / 2$ & $3 / 4$ & $1 / 2$ & $3 / 4$ & $1 / 2$ & $3 / 4$ & $2 / 3$ & $3 / 4$ \\
\hline
\end{tabular}


$L \quad$ is the free-space path loss in $\mathrm{dB}$ :

$$
L=L_{0}=20 \cdot \log _{10}\left(4 \pi \cdot d_{0} / \lambda\right)
$$

where:

$\lambda$ is the carrier wavelength in [m],

$d_{0}$ is the breakpoint distance in [m] up to which it is possible to calculate free space path loss using equation (3).

Relation (2) represents obvious form of equation for RF output power level calculation.

ETSI propagation model (European Telecommunications Standards Institute)

ETSI accepted a large scale fading propagation model used for mobile communication applications, [6]. To account for the increased path loss coefficient, the total path loss is split up into two contributions:

$$
L=L_{0}+L_{1} \text {, }
$$

where:

$$
L_{0}=20 \cdot \log _{10}\left(4 \pi \cdot d_{0} / \lambda\right), d_{0}=15 \mathrm{~m}, d \leq d_{0} \text {, is free }
$$

space transmission path loss,

$$
L_{1}=10 \cdot \log _{10}\left(d / d_{0}\right)^{n}, d_{0}<d \text {, is the path loss }
$$

assuming a path loss coefficient $n=2.7$

beyond the breakpoint distance $d_{0}$ in [m],

$\lambda$ is the carrier wavelength in [m],

$d$ is communication distance in [m]. mittee)

ECC propagation model (Electronic Communications Com-

Improved path loss factor of a large scale fading propagation model is presented in [7]. Signal degradation beyond the first breakpoint distance is taken into account and path loss corrections are defined. ECC propagation losses $\mathrm{L}$ are considered as the conventional expression up to $d_{0}(3)$ and the corrected expression beyond:

$$
\begin{aligned}
& L=L_{0}=20 \cdot \log _{10}\left(4 \pi \cdot d_{0} / \lambda\right), \quad d \leq d_{0} \\
& L=L_{1}=20 \cdot \log _{10}\left(4 \pi \cdot d_{0} / \lambda\right)+10 n_{0} \cdot 10 \log _{10}\left(d / d_{0}\right) \\
& d_{0}<d \leq d_{1} \\
& L=L 2=20 \cdot \log _{10}\left(4 \pi \cdot d_{0} / \lambda\right)+10 n_{0} \cdot 10 \log _{10}\left(d / d_{0}\right)+ \\
& +10 n_{1} \cdot 10 \log _{10}\left(d / d_{1}\right) \\
& d_{1}<d
\end{aligned}
$$

where:

$\lambda$ is the carrier wavelength in $[\mathrm{m}]$, $d \quad$ is communication distance in [m],

$d_{0}$ is the breakpoint distance in $[\mathrm{m}]$

(up to which it is possible to calculate free space path loss), $d_{1}$ is the breakpoint distance in [m],

$n_{0}, n_{1}$ are path loss factors.

ECC performed studies to estimate the impact from FWA (Fixed Wireless Access) systems on the RTTE on-board units (OBU), including false wake up detection and its effect on OBU battery life. Breakpoint distances and path loss factors were defined on the basis of the studies, table 3 .

Parameters of propagation

Table 3

\begin{tabular}{|l|c|c|c|}
\hline & Urban & Suburban & Rural \\
\hline Breakpoint distance $d_{0}[\mathrm{~m}]$ & 64 & 128 & 256 \\
\hline $\begin{array}{l}\text { Path loss factor } \mathrm{n} 0 \text { beyond the first } \\
\text { breakpoint }\end{array}$ & 3.8 & 3.3 & 2.8 \\
\hline Breakpoint distance $d_{1}[\mathrm{~m}]$ & 128 & 256 & 1024 \\
\hline $\begin{array}{l}\text { Path loss factor } \mathrm{n} 1 \text { beyond the second } \\
\text { breakpoint }\end{array}$ & 4.3 & 3.8 & 3.3 \\
\hline
\end{tabular}

\section{Simulation}

Referring to equation (2) and radio propagation models, it is clear that RF output power level of transmitter, $P_{T}$, is depended on:

$P_{R}$ receiver sensitivity in $\mathrm{dBm}$,

$G_{T}$ transmit antenna gain in $\mathrm{dBi}$,

$G_{R}$ receive antenna gain in $\mathrm{dBi}$,

$L$ path loss propagation model in $\mathrm{dB}$,

$\lambda$ carrier wavelength in $[\mathrm{m}]$,

$d$ communication distance in $[\mathrm{m}]$,

$d_{0}, d_{1}$ breakpoint distances in [m],

$n_{0}, n_{1}$ path loss factors.

\section{Receiver sensitivity: $\boldsymbol{P}_{\boldsymbol{R}}[\mathrm{dBm}]$}

The minimum receive sensitivity (OBU or RSU) specifies the required receive input power (i.e., at the antenna connection) including an implementation margin of $5 \mathrm{~dB}$ for a receiver noise figure of $10 \mathrm{~dB}$ and a BER of $10^{-5}$, table 4 [8]. $P_{R}$ is defined in compliance with a communication channel bandwidth for corresponding data rate.

Referring to simulation, value of $P_{R}$ is selected on the basis of information in table 1 :

$$
P_{R}=-72 \mathrm{dBm}(B W=10 \mathrm{MHz} \text {, data rate }=6 \mathrm{Mbits} / \mathrm{s}) .
$$

Transmit and receive antenna gains: $G_{T}, G_{R}[\mathrm{dBi}]$

ITS applications expect $10 \mathrm{dBi}$ antenna gain for road-side unit (RSU), $8 \mathrm{dBi}$ or $5 \mathrm{dBi}$ antenna gain for on-board unit (OBU) of a vehicle, [4].

Appealing to simulation, values of $G_{T}$ and $G_{R}$ are selected in compliance with Inter-vehicle (IVC - channels numbers: 178, 180) 
or roadside-to-vehicle ( $\mathrm{R} 2 \mathrm{~V}$ - channel number: 176) communication: $G_{T}=5 \mathrm{dBi}, G_{R}=5 \mathrm{dBi}$ (IVC communication).

Path loss propagation model: $L$ [dB]

Minimum receiver sensitivity for a $\mathrm{BW}$ of $10 \mathrm{MHz}$

Table 4

\begin{tabular}{|c|c|}
\hline Data rate $[\mathrm{Mbits} / \mathrm{s}]$ & Minimum sensitivity $[\mathrm{dBm}]$ \\
\hline 3 & -85 \\
\hline 4.5 & -84 \\
\hline 6 & -72 \\
\hline 9 & -80 \\
\hline 12 & -77 \\
\hline 18 & -70 \\
\hline 24 & -69 \\
\hline 27 & -67 \\
\hline
\end{tabular}

Referring to simulation purposes, a radio wireless propagation model must be proposed in compliance with practical applications. Relating to above mentioned models, value of carrier wavelength $\lambda$ is corresponding with the channel type (channel number) used for ITS services, [3]: $\lambda=0.0508 \mathrm{~m}$ (channel type: G5CC; channel number: 180; centre frequency $5.9 \mathrm{GHz}$ ). Breakpoint distances $d_{0}, d_{1}$ as well as path loss factors $n_{0}, n_{1}$ are defined by practical measurements or standards: equations (3), (5), (6) and table 3.

Communication distance (range): $d[\mathrm{~m}]$

It is distance between two communication units, i.e. transmitter and receiver (RSU and $\mathrm{OBU}, \mathrm{OBU}$ and $\mathrm{OBU}$ ). Appealing to simulation, values of $d$ are defined up to the communication range limit: $1000 \mathrm{~m}$, table 5 .

Table 5 presents results of calculations based on theoretical models representing relation of TX power level of the transmit unit and the distance between on-board units of two vehicles. Calculations were done for several radio propagation models. A free-space model (M1) expects no obstacles between transmitter and receiver, i.e. propagated waveform is not degraded (path loss coefficient $n=2$ ). ETSI model (M2) expects line-of-sight communication with severely destructed first Fresnel zone (path loss coefficient is in the range: $n=2.5 \ldots 3 ; n=2.7$ was selected; the pass loss coefficient for non-line-of-sight conditions would be in the range: $n=3 \ldots 5$ ). ECC models (M3, M4, M5) were derived from mobile communi- cation ones. They respect three different ITS environments: urban, suburban, rural. Path loss coefficients were adapted for ITS applications.

Referring to differences between estimated values for a defined distance of the models (table 5), validity of the models had to be verified by practical measurements in ITS environments. Unfortunately, this step was impossible to realize due to lack of technical equipment. That is why the results of simulation could be interpreted only on theoretical basis.

TPC dynamic range for channel number: 180 is $30 \mathrm{~dB}$. Minimal TX power level is defined on the level of $3 \mathrm{dBm}$, maximal is equal to $33 \mathrm{dBm}$. Appealing to table 5, theoretical TX power values lower than minimal limit were replaced by $3 \mathrm{dBm}$ and higher ones than maximal limit by $33 \mathrm{dBm}$. Adaptation of the values is in compliance with defined TX power limits as well as practical realization of TPC block. Increasing TX power to minimal limit will improve reliability of communication between vehicles. Unfortunately, decreasing TX power to maximal limit will shorten communication distance, i.e. communication range limit $1000 \mathrm{~m}$ does not need to be met. Looking for the solution to solve this topic, communication range limits at maximal $\mathrm{TX}$ power $=33 \mathrm{dBm}$ were calculated, table 6 .

Communication range limits at maximal

Table 6 transmit power $33 \mathrm{dBm}$

\begin{tabular}{|ll|c|c|}
\hline \multirow{2}{*}{ Models } & \multirow{2}{*}{ Communication range limit [m] } \\
\cline { 3 - 4 } & & $G_{R}=5 \mathrm{dBi}$ & $G_{R}=8 \mathrm{dBi}$ \\
\hline Free-space model & $\mathrm{M} 1$ & 1278 & 1805 \\
\hline ETSI model & $\mathrm{M} 2$ & 405 & 523 \\
\hline ECC model: Urban & $\mathrm{M} 3$ & 279 & 328 \\
\hline ECC model: Suburban & $\mathrm{M} 4$ & 471 & 565 \\
\hline ECC model: Rural & $\mathrm{M} 5$ & 933 & 1033 \\
\hline
\end{tabular}

The values in table 6 show that improvement of communication range limits for inter-vehicle communication (IVC) via selected channel type and defined minimum receiver sensitivity could be realized by increasing the receiver antenna gain of the vehicle. Models M2, M3 and M4 did not meet expected $1000 \mathrm{~m}$ limit neither after increasing the receiver antenna gain. In this case it

Dependency of TX power level of the transmit unit on the distance between

OBUs of two vehicles (channel number: 180; TX power $=P_{T}+G_{T}$ )

\begin{tabular}{|ll|l|c|c|c|c|c|c|}
\hline Models & & Distance [m] & 10 & 50 & 100 & 250 & 500 & 1000 \\
\hline Free-space model & M1 & TX power [dBm] EIRP & 3 & 5 & 11 & 19 & 25 & 31 \\
\hline ETSI model & M2 & TX power [dBm] EIRP & 3 & 8.5 & 17 & 27.5 & 33 & 33 \\
\hline ECC model Urban & M3 & TX power [dBm] EIRP & 3 & 5 & 14.5 & 31 & 33 & 33 \\
\hline ECC model Suburban & M4 & TX power [dBm] EIRP & 3 & 5 & 11 & 23 & 33 & 33 \\
\hline ECC model Rural & M5 & TX power [dBm] EIRP & 3 & 5 & 11 & 19 & 27.5 & 33 \\
\hline
\end{tabular}


would be necessary to arrange OBU with better minimum receiver sensitivity. Unfortunately, data rate had to be decreased to guarantee reliable communication. Referring to values in tables 5 and 6, it is possible to conclude that ECC models estimate TX power in compliance with specific features of ITS environments.

Appealing to values of TX power in tables 5 and 6 , it is possible to state:

- Model M1: in spite of the fact that communication range limit of $1000 \mathrm{~m}$ is met and full TPC range of $30 \mathrm{~dB}$ is utilized the model would be valid only for very short distance free-space IVC, R2V communication;

- Model M2: communication range is shorter than $523 \mathrm{~m}$; better TX power estimation could be expected for urban and suburban environments rather than rural one;

- Model M3: communication range is shorter than $328 \mathrm{~m}$; model could be used for TX power estimation in case of urban environment;

- Model M4: communication range is shorter than 565 m; model could be used for TX power estimation in case of suburban environment;

- Model M5: communication range met the limit of 1000 m; model could be used for TX power estimation in case of rural environment;

\section{Conclusion}

V2X communication system plays a core role of inter-vehicle as well as road-side-to-vehicle communication allowing development of services focused on the improvement of road safety and traffic efficiency (driving assistance: co-operative awareness, road hazard warning; speed management; co-operative navigation; location based services, etc.). The article presents fundamentals of transmit power control analysis including simulation results for inter-vehicle communication. Road-side-to-vehicle communication could be analyzed in a similar way. Future research steps would be focused on: validation of presented theoretical models, incorporating traffic density aspects into models and analysis of transmit power control from the basic set of applications point of view.

\section{Acknowledgement:}

This contribution is the result of the project implementation: Centre of excellence for systems and services of intelligent transport, ITMS 26220120028 supported by the Research \& Development Operational Programme funded by the ERDF.

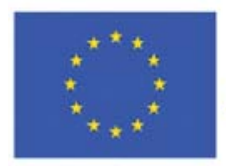

Európska únia

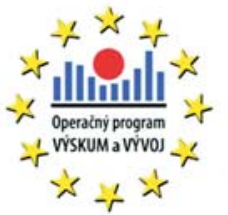

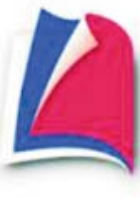

Agentúra

Ministerstva školstva, vedy, výskumu a športu SR pre štrukturálne fondy EÚ

"Podporujeme vyskumne aktivity na Slovensku/Projekt je spolufinancovany zo zdrojov EU."

\section{References}

[1] MICEK, J., KAPITULIK, J.: Car-to-car Communication System. In: Proc. of the International Multiconference on Computer Science and Information Technology, Vol. 4, 2009, ISBN 978-83-60810-22-4, ISSN 1896-7094, pp. 627-631.

[2] ETSI TR 102-492-2 V1.1.1, July 2006: Electromagnetic Compatibility and Radio Spectrum Matters (ERM).

[3] ETSI ES 202663 V1.1.0, November 2009: ITS; Physical and Medium Access Control Layer.

[4] ETSI EN 302571 V1.1.1, September 2008: ITS; Radiocommunications Equipment Operating in the $5855 \mathrm{MHz}$ to $5925 \mathrm{MHz}$ frequency band.

[5] www.wikipedia.com, Friis Transmission Equation.

[6] SKLAR, B.: Digital Communications, Fundamentals and Applications. 2001, Prentice Hall, ISBN 0-13-084788-7.

[7] ECC Report 101: Compatibility Studies in the Band 5855- $5925 \mathrm{MHz}$ between ITS and other Systems.

[8] ETSI TR 102-492-1 V1.1.1, June 2005: Electromagnetic Compatibility and Radio Spectrum Matters - Part 2, ITS. 